\title{
The Use of the Fluorescence to the Study of the Water Quality
}

\author{
Belén ESTÉBANEZ ${ }^{1}$, Julio GUTIÉRREZ-RÍOS ${ }^{2}$, Jara VASSAL 'LO-SACO ${ }^{2}$, \\ Antonio TAZÓN ${ }^{3}$, Juan VASSAL'LO-SANZ ${ }^{4}$ \\ ${ }^{1}$ Dept. of Biology, Faculty of Sciences, Autonomous University of Madrid, Darwin 2, 28049, Madrid (Spain) \\ ${ }^{2}$ Dept. of Photonic Technology, Faculty of Informatics, Polytechnic University of Madrid, \\ Campus Montegancedo s/n, 28660, Madrid (Spain) \\ ${ }^{3}$ Dept. of Communications Engineering, Telecommunications School, University of Cantabria, \\ Avda. los Castros s/n, 39005 Santander (Spain) \\ ${ }^{4}$ Lab. of Antennas Technology, Institute of Applied Physics - CSIC, Serrano 144, 28006 Madrid (Spain)
}

belen.estebanez@uam.es,jgr@fi.upm.es,vassallio@fi.upm.es, antonio.tazon@unican.es, ltqvs22@ifa.cetef.csic.es

\begin{abstract}
We present a work proposal now in course that is based on the study of the fluorescence in cyanobacteria and toxicity, and the possibility of detecting their presence in freshwater environment, with a direct application in water assessment. The proposal is a consequence of a previous study about the fluorescence generated by hydrocarbon residue on the sea surface.

In the first part of this work we present a review of results obtained from the analysis of hydrocarbon samples from the "prestige" oil spill accident and other referential hydrocarbons. In the second part we show the capability of this technique for the development of probes to explore the water quality.
\end{abstract}

\section{Keywords}

Fluorosensing, fluorometry, detection of contaminant substances.

\section{Introduction}

The ecological disaster of "Prestige", derived from the sinking of the tanker ship of this name at the Galician coast in the North-West of Spain, suggested the idea of the development of a method or instrument to detect the presence of small quantities of hydrocarbon residues on the sea surface or on the coasts, as it is done in other countries [1], [8], [10].

A working group headed by the Polytechnic University of Madrid, and through the University of Santiago de Compostela, presented a proposal to study the viability of an airborne instrument based on the identification of the fluorescence signature of oils and fuel substances, using optical instrumentation off the shell. This work has been just finished [6], and the obtained results suggest new applications of this technology to the assessment of the water quality.

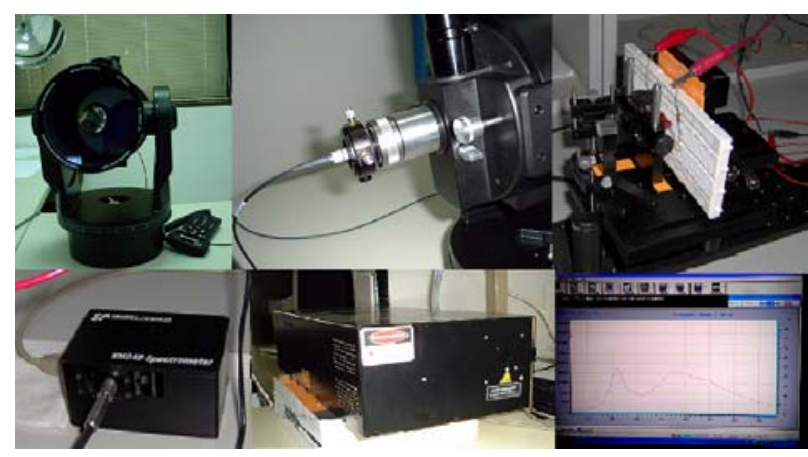

Fig. 1. Elements of our laboratory instrument.

\section{The Hydrocarbon Signature}

As it is known, the spectral response of fluorescence is extended to wavelength greater than the incident signal, and it can be detected at distance, through a zoom lens [7].

The spectral signal can be analyzed by software which was developed with the objective of discriminating the fluorescence signature of samples, by means of a comparison with a database.

Fig. 1 shows the laboratory components of an experimental instrument designed to obtain the fluorescence signature at a distance of several meters (i.e. 5 to 20). This prototype allows the acquisition of the required database for the identification of the samples.

The essentials of this experimental instrument [6] consist of a nitrogen laser generator that works in the ultraviolet part of the spectrum, used to induce fluorescence on the target. The instrument is completed with a conventional portable astronomical telescope coupled to a collector of optical radiation, both designated to capture the fluorescence emission. A diffraction-type spectrometer covering the visible part of the spectrum, where the hydrocarbons response is located, provides the spectro-fluorometry. Finally, a personal computer supports the software for spec- 
tra graphic representation and recording, as well as the discriminator and spectra identifier.

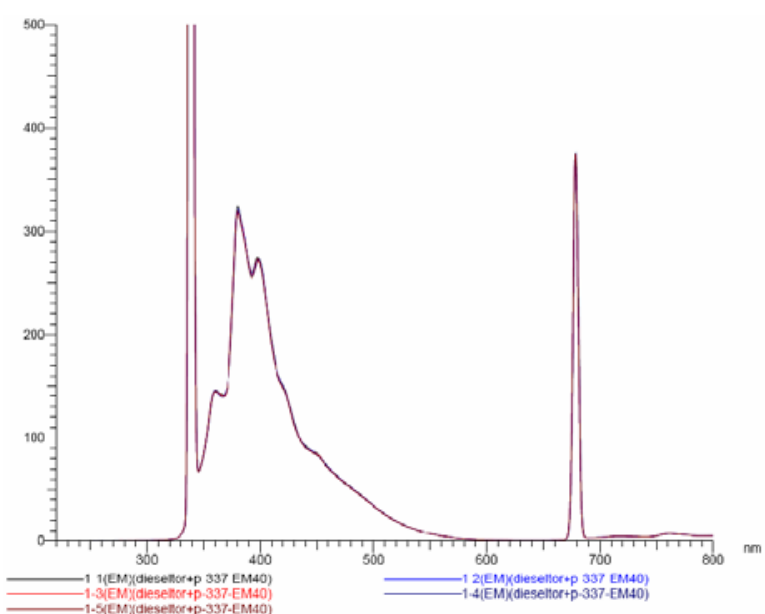

Fig. 2. Fluorescence of Diesel A.

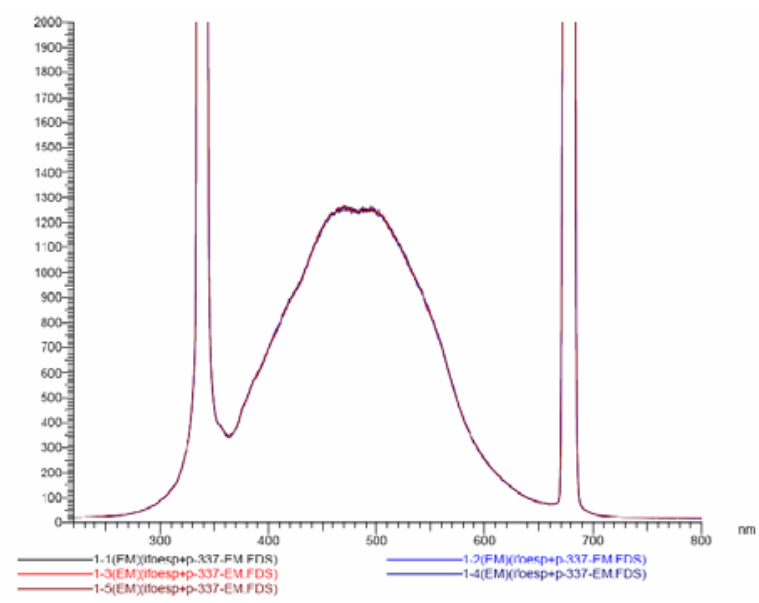

Fig. 3. Fluorescence of diesel IFO380.

\section{Results of the Instrument Prototype}

Figs. 2, 3, 4, 5 and 6 show the fluorescence signature of several hydrocarbon samples; some of them are different diesel oils (Figs. 2, 3 and 4), and the other ones (Figs. 5 and 6), are different residues from "Prestige". As it can be seen in this figure, each sample presents a different response, and the fluorescence trace can be used to identify the kind of substance to be tested.

The "Prestige" hydrocarbon type was IFO380, used as a fuel. In Fig. 5 the fluorescence trace of the "Prestige" residue acquired from a container in Galicia two years after the ecological disaster is represented.

Comparing Figs. 3 and 5, both traces have similar shape, with a maximum emission at the same wavelength. The trace of Fig. 3 was obtained from a sample provided by Repsol YPF, the trace of Fig. 5 from the "Prestige" tanks.

The sample of Fig. 6 is also related with the "Prestige" disaster, but it is from a remaining fluid collected in a retaining pond in Galicia, used as a dump of the oil spill of
"Prestige". The fluorescence trace changes, and the emission intensity goes down.

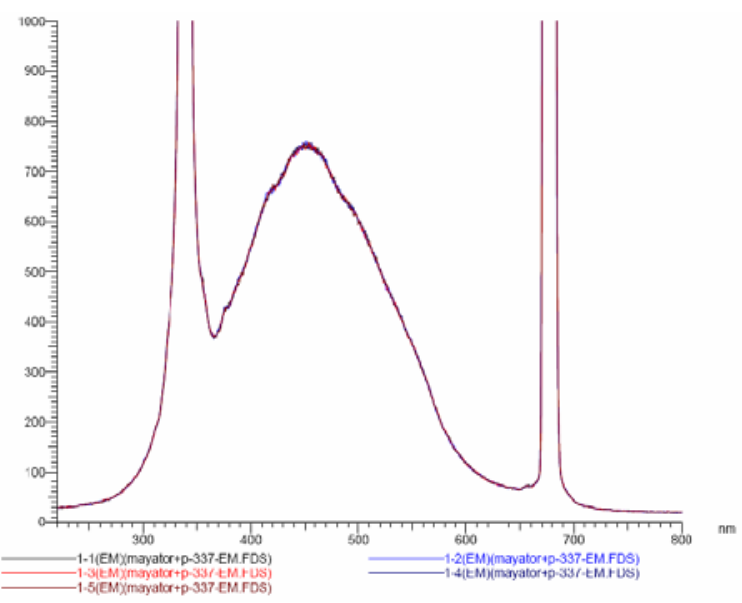

Fig. 4. Fluorescence of "maya crude-oil”.

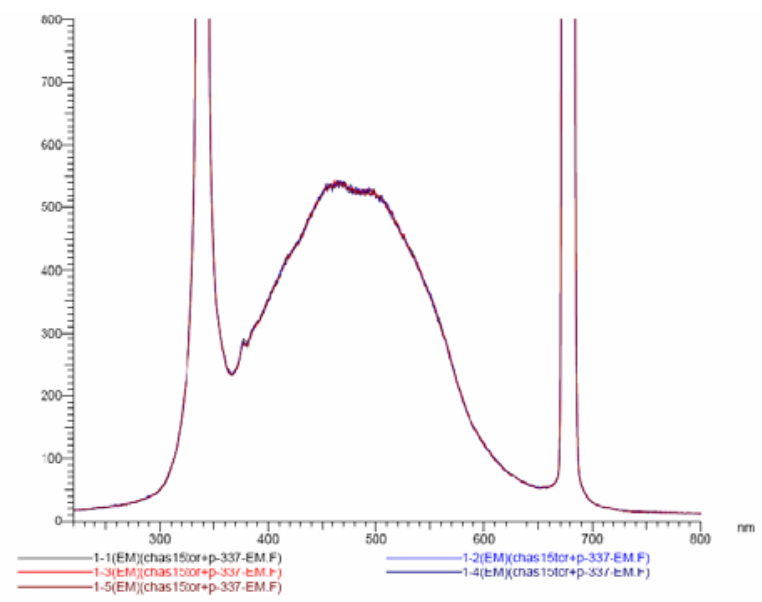

Fig. 5. Fluorescence of "Prestige” residue sample 1.

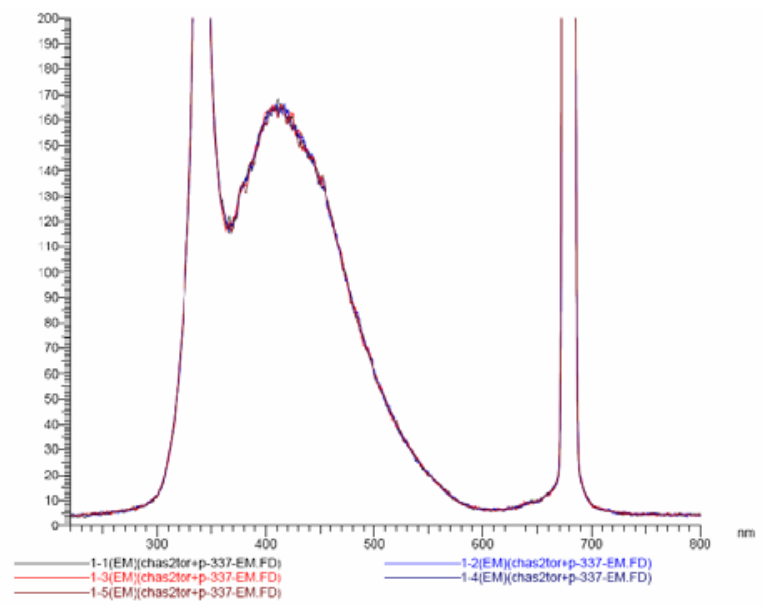

Fig. 6. Fluorescence of "Prestige” residue sample 2.

This result shows that it has been got an effective experimental instrument [6] demonstrating the viability of a sensor for the detection and identification of hydrocarbon residues on the water surface.

Depending on the characteristics of the equipment, available distance between sample and laser transmitter for 
an airborne instrument can be found. In this experimental model the sample is placed at $12 \mathrm{~m}$ from the laser transmitter. The experience shows also that small sensors can be designed for the vigilance of any water store or conduction. In this case, a full time vigilance of water quality can be achieved.

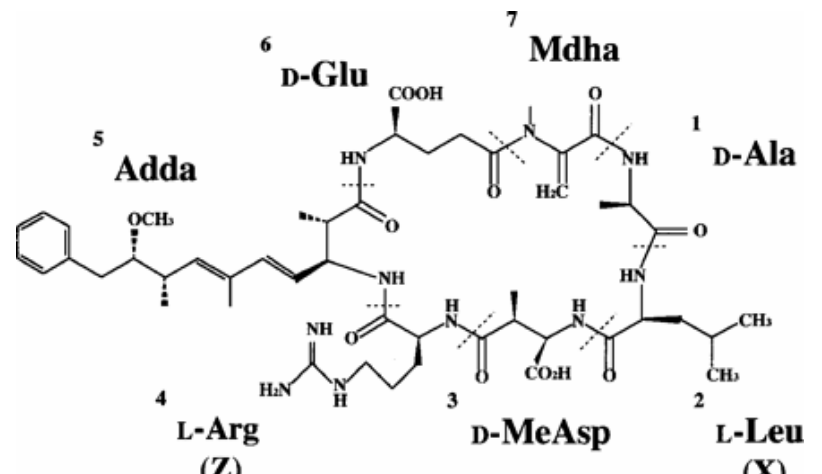

(Z)

$$
\text { D-Glu }
$$

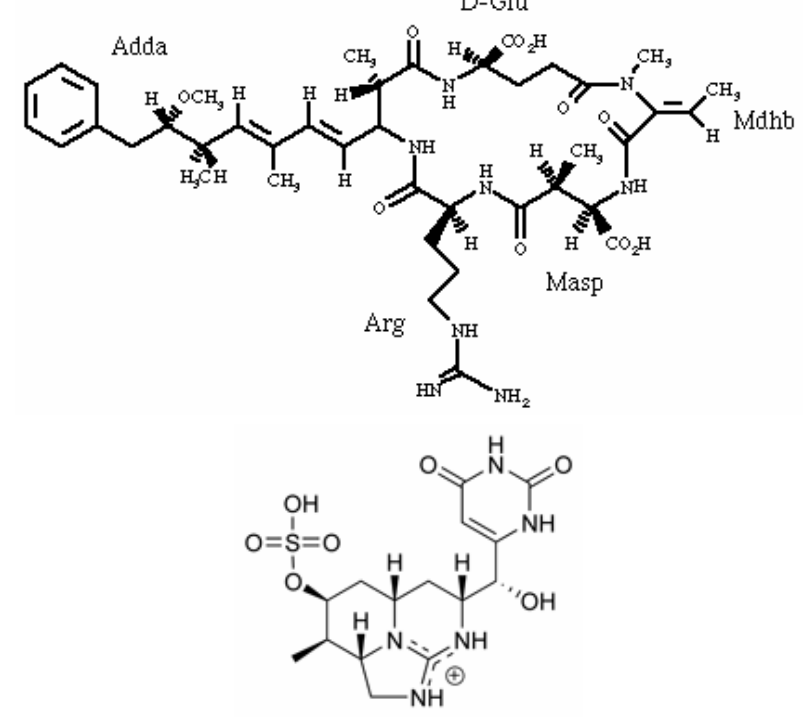

Fig. 7. Structures of some toxins in cyanobacteria.

\section{The Technique Referred to Cyanobacteria Signature}

This fluorescence technique may be also used for other objectives. For example, we are now involved on the study of its viability for the detection of cyanobacteria, and their associated toxicity in freshwater environments [2]. This could have a deep impact in public health policies through the improvement of the assessment of drinking water quality, recreational water pools, etc.

This study is based on the possibility to obtain a signature of the molecular structure of biomarkers of this and other algal groups [8]. We are undertaking a direct research line, targeting the photosynthetic pigments and different toxins of cyanobacteria. Figs. 7 and 8 show the structural composition of some cyanobacterial toxic substances [5]. The objective of our proposal is to demonstrate that the presence of conjugated double bond systems and relative motion restriction cyclic group in the molecular structure of these substances could produce a specific fluorescence signature [7].
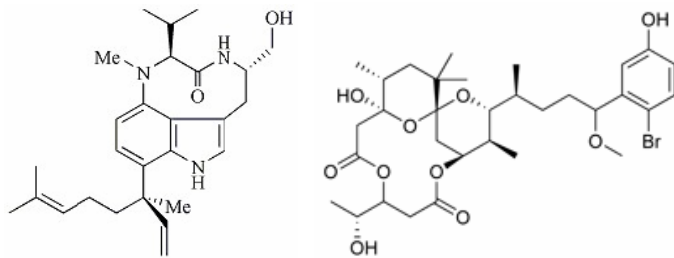

Fig. 8. Structures of some toxins in cyanobacteria.

This technique may be used also following an indirect approach, targeting the non-toxic photosynthetic pigments of algal cells. This could lead to the identification of other dangerous algal groups, such as the highly toxic dinoflagellates, which are responsible of the "red tides", affecting with a deep impact mussel cultures.

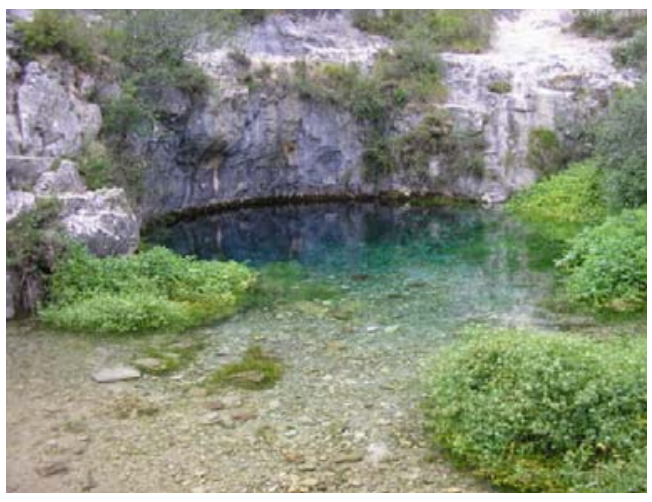

Fig. 9. Sampling area: river source.

This viability study, now in progress, is included on a research project aiming at the characterization of the water quality of a mountain river in the North of Spain [3], [4]. Figs. 9 and 10 show some views of the sampling site.

The area of study in "Arroyo del Pozo Azul” and its vicinities, an outlet from the Burgos Karst System, in the Natural Reserve "Hoces del Alto Ebro y Rudrón”, with several points of samples acquisition including different characteristics, clean water at the river source area (Figs. 9 and 10), and "non-clean" water at an area close to a fish farm outlet (Fig. 11). Some university students are also collaborating in the acquisition and identification of samples, as it can be seen in Fig. 10.

\section{New Probes to Water Study}

A final part of the study consists in the design of a "multi-probe" to the whole parameterization of a river or a water store [6]. The idea is to have a central unit controlling several and different kind of probes. We have just design of the control unit that would save all data from connected probes periodically in a text file. The file can be sent to the data processing centre, using different systems, depending of the distance between the unit and the processor centre. 


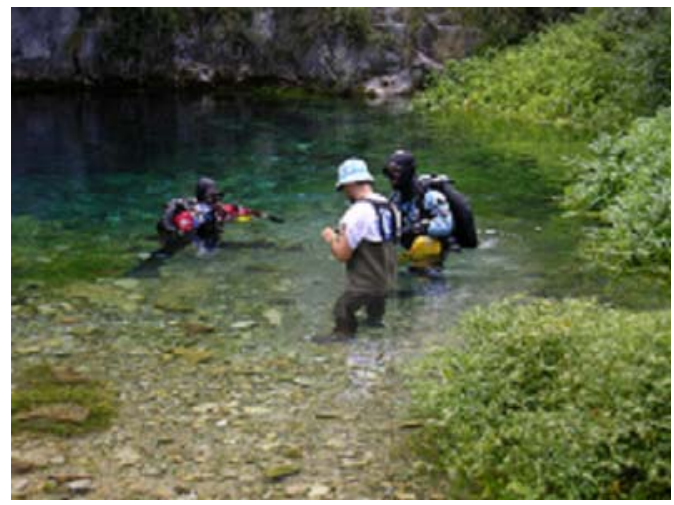

Fig. 10. Sampling area: acquisition of samples at river bottom.

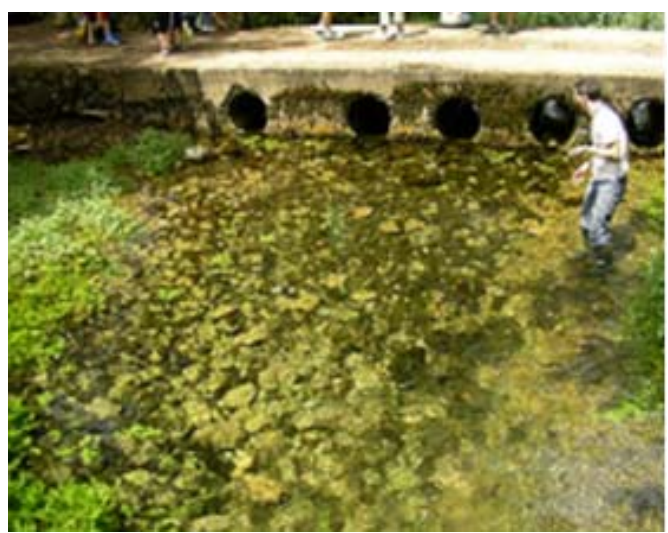

Fig. 8. Sampling area: Close to a fish farm outlet.

Presently, we are testing a "multi-probe" with 3 commercial temperature probes. The prototype saves data on a small card, which can be periodically replaced by an empty card when its memory is full. The design allows saving data every 5 minutes, with a life time of 1 year without replacement of the card. All the parameters of control can be modified by specific software.

This has been the first step in the design of a "multiprobe”. Of course, what we aim is to include fluorometry in the probe. As a matter of fact, remote sensing is a very flexible technique for global monitoring of an aquatic media or so, but in the referred case of cyanobacteria, the sensibility could be not enough, given that noticeable toxicity can be produced by a very low concentration of cyanobacteria, difficult to be detected.

In this case, the only possibility to detect toxicity is by means of underwater sensors of fluorescence of high sensitivity. We already have built a short-distance instrument which has provided some experimental conclusions. But our project contemplates a much advanced device, with a small submersible and water-resistant part easy to be maintained. Fig. 12 shows a scheme of this device.

In this case, the source of light is supposed to be continuous, and spectrometry, sequential, in order to be able to capture fluorescence with only one high-sensibility receiver. In this case, capture time is not a critical parameter. On the other hand, data acquisition and collection system is similar to that described for current multi-probe.

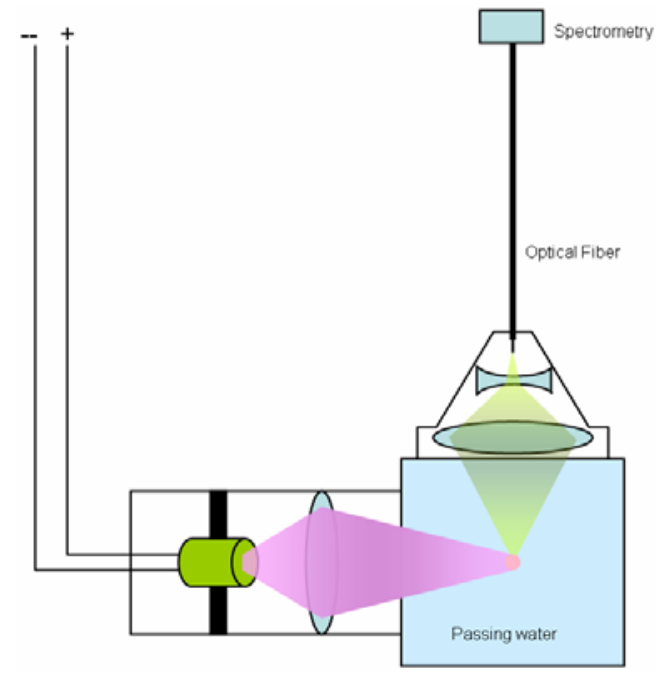

Fig. 12. Scheme of a fluorometric underwater probe.

\section{Conclusions}

We have presented in this paper some of the partial results of a study, which is now in progress, about the viability of fluorescence sensors for the detection and identification of hydrocarbon and cyanobacteria. This research line is currently focused in contributing to the assessment and control of the water quality.

Our previous results show that it is possible to identify petroleum-derived substances on the sea surface and coasts, by means of fluorescence detection.

The research aiming at the application of this technique to the identification of cyanobacteria and their associated toxicity is now in progress.

\section{Acknowledgements}

One part of the research described in the paper was financially supported by the "Fundación Arao" from the Spanish Autonomous Community of Galicia, and afterwards by internal support of the UPM and CSIC through a Collaboration Agreement.

Authors acknowledge these institutions as well as to the courtesy of Repsol YPF providing the samples of hydrocarbons to the development of this work, and Sogarisa providing samples of the Prestige spills. Also to the UPM and UAM students collaborating in this proposal.

\section{References}

[1] ZIELINSKI, O., ANDREWS, R., GÖBEL, J., HANSLIK, M., HUNSÄNGER, T. , REUTER, R. Operational airborne hydrographic laser fluorosensing. Report of the Bundesanstalt für Gewässerkunde in Lidar Remote Sensing on Land and Sea. Rainer Reuter (Editor) EARSeL, Proceedings 1, 2001, p. 53-60.

[2] ESTÉBANEZ, B., GUTIÉRREZ-RÍOS, J., VASSAL'LO-SACO, J., TAZÓN, A., VASSAL'LO-SANZ, J. Nuevas técnicas para el studio de la calidad del agua. In CONAMA8 Spanish Congress about the Environment. Madrid (Spain), 2006. 
[3] JUBERA, E., FERNÁNDEZ-MAZUECOS, M. , ESPÍ, A., LUNA, J., MORILLO, L., QUIROGA, A., RODRÍGUEZ-POZO, M., TOLEDO, J., ORGAZ, D., ESTÉBANEZ, B., VASSAL'LO, J. Caracterización de comunidades bentónicas de cianobacterias en el Arroyo Pozo Azul (Covanera, Burgos). In XVI Simposio Botánica Criptogámica. León, 2007.

[4] JUBERA, E., FERNÁNDEZ-MAZUECOS, M., ESPÍ, A., QUIROGA, A., LUNA, J., OLIVAS, A., ESTÉBANEZ, B., VASSAL’LO, J. Comunidades de cianobacterias bentónicas en el enclave del Pozo Azul (karst de Burgos). In VIII Coloquio Internacional de Botánica Pirenaica. León, 2007.

[5] CHORUS, I., BARTRAM, J. Toxic cyanobacteria in water: a guide to their public health consequences, monitoring and management. World Health Organization, 1999.

[6] GUTIÉRREZ-RÍOS, J., VASSAL'LO-SACO, J., SOTO, I., GALLEGO, E., MARAVER, P., ESTEBAN, A., MEDRANO, A., VASSAL' LO-SANZ, J. Técnicas de teledetección inteligente de vertidos de hidrocarburos en medio marino (Report Fluorosensing). Final Report - Reference: TTIVHMM02_Final_2006 - Fundación Arao - Xunta de Galicia, 2006.

[7] LAKOWICZ, J. R. Principles of Fluorescence Spectroscopy. Third Edition. Springer, 2006.

[8] LEE, R. E. Phycology. $2^{\text {nd }}$ ed. Cambridge University Press, 1989.

[9] BABICHENKO, S., DUDELZAK, A., LAPIMAA, J., LISIN, A., PORYVKINA, L., VOROBIEV, A. Locating water pollution and shore discharges in costal zone and inland waters with FLS lidar. European Association of Remote Sensing Laboratories: EARSeL eProceedings, 5 1/2006.

[10] ZIELINSKI, O., HENGSTERMANN, T., MACH, D., WAGNER, P. Multispectral information in operational marine pollution monitoring: A data fusion approach. In Fifth International Airborne Remote Sensing Conference, San Francisco, California, 2001.

\section{About Authors}

Belén ESTÉBANEZ was born in Madrid (Spain) in 1967. She graduated in Biology and obtained her PhD in Botany at Universidad Complutense de Madrid (UCM). She has worked in electron microscopy and botany at Hiroshima University (Japan), Real Jardín Botánico (Madrid), and, presently, at Universidad Autónoma de Madrid (UAM). She has been involved in several projects on non-vascular plants, especially on functional morphology and ultrastructure, and currently is collaborating in the characterization of continental aquatic systems using macrophytes and cyanobacterial communities.

Julio GUTIÉRREZ-RÍOS was born in Valencia, Spain, in 1951. He is a Telecommunication Engineer by the Universidad Politécnica de Madrid (UPM) and he got the PhD degree by the same University in 1981. Assistant professor of the UPM in 1977, tenured professor in 1985 and full professor in the area of Computer architecture and technology in 1987, always in the Facultad de Informática (FI) of the UPM. In 1989 he was designated deputy director of the Instituto Nacional de Tecnología Espacial (INTA) that is the space agency in Spain. After three years in this charge, he came back to the UPM as a full professor and proposed a new program in INTA about Synthetic Aperture Radar (SAR), program that directed along seven years, till 1999. Also he has been Director of the Dept. of Circuits Theory and Electronics of the FI of the UPM, and the Dept. of
Photonic Technology of the UPM in which he actually remains, as well as Vice Dean for Research and PostGraduated Studies of the FI-UPM. His main subjects of research are remote sensing techniques, fluoro-sensing, signal processing, SAR processing and soft-computing based systems. He is author of more than 70 papers.

Jara VASSAL'LO-SACO was born in Madrid (Spain) in 1976. Graduated in Biology at the UCM in 2000, she is going to obtain her $\mathrm{PhD}$ degree at the Universitat de Girona (UdG) in 2008. Since 2001 she is working on cyanobacteria communities in streams, their toxicity in natural systems and ecological parameters linked to their dynamics. In this area, she obtained a scientific degree by the UdG in 2003. In 2005, she joined a Working Group of the UPM involved on fluorescence studies, on the development of a laboratory for contaminant substances handling, and collaborating on the study of hydrocarbons fluorescence and fluorodetection systems for water quality applications. Since 2006 she is also collaborating with the UAM in different activities related with the characterization of benthic communities in the "Pozo Azul" site and the training of biology students in cyanobacteria identification.

Antonio TAZÓN was born in Santander, Spain, in 1951. He received the M. Sc. Degree in Physics in 1978 and received the Ph.D. in Physics in 1987, both from the Universidad de Cantabria (UC), Santander. He has carried out research on analysis and optimization of non-linear microwave active devices and circuits in both hybrid and monolithic technologies. Currently, his main research areas are active microwave circuits (linear and large-signal modeling, small signal intermodulation of $\mathrm{GaAs}$ and $\mathrm{Si}-\mathrm{Ge}$ devices) and their applications in non-linear computer aided design, as well as active arrays and reflectors with electronic beam control. He was a Professor with the Dept. of Electronics, UC, from 1991 to 1995. Since 1996, he has been a Professor at the Dept. of Communication Engg. in the same University. In parts of 1985 and 1986, he carried out stages at IRCOM Dept., University of Limoges, France, working in non-linear modeling and loadpull techniques. He has participated in Spanish and European projects in non-linear modeling (Esprit proj. 6050 MANPOWER), and microwave and millimeter wave communication circuits and systems (projects PlanSAT, CABSINET, etc).

Juan VASSAL'LO-SANZ was born in Madrid, Spain, in 1949. Physics by the UCM in 1975, PhD by the same university in 1983. Since 1976 working on EM propagation on anisotropic materials, microwaves circuits and antennas in Antennas Technology Laboratory of Inst. of Applied Physics. He developed land mobile antennas through GEO satellite for communication systems, and flat antennas at space environment under ESA Contracts. Since 1986, he was involved in several antenna projects with Spanish Universities, Industrial Companies, and other European Groups, through several COST Actions. Now, he is involved in developing passive and active reflectarrays, Fresnel reflectors, interferometric radiating systems, the study of fluorodetection systems for water quality applications. 